\title{
Feasibility and Safety of Low Pressure Pneumoperitoneum for Laparoscopic Cholecystectomy: A Prospective, Randomized, Triple-Blinded Trial
}

\author{
Agarwal Nitin $^{1 *}$, Sharma Ashish ${ }^{1}$, Gupta Arun ${ }^{1}$, Tyagi Asha ${ }^{2}$, Sethi AK ${ }^{2}$, Kaur Navneet ${ }^{1}$ \\ ${ }^{1}$ Department of Surgery, University College of Medical Sciences and Guru Tegh Bahadur Hospital, Delhi, India \\ ${ }^{2}$ Department of Anesthesiology and Critical Care, University College of Medical Sciences and Guru Tegh Bahadur \\ Hospital, Delhi, India
}

Received: December 15, 2016; Accepted: February 25, 2017; Published: April 20, 2017

*Corresponding author: Agarwal Nitin, Department of Surgery and Anesthesiology and Critical Care, University College of Medical Sciences and Guru TeghBahadur Hospital, Delhi, India, E-mail: drnitinagarwal76@gmail.com

\begin{abstract}
Background: Laparoscopic cholecystectomy (LC) at pnemoperitoneum (PP) pressures of 12-15 mm Hg is established for symptomatic gallstones. Metabolic and cardiopulmonary concerns and, pain may be minimized by low pressure PP, however, insufficient evidence exists for its routine use.

Methods: A prospective, randomized, triple-blinded trial was conducted in a tertiary care teaching hospital in Delhi, India, over a 16-month period. A total of 60 patients were randomized into two groups of 30 each ( $8 \mathrm{mmHg}$ and $12 \mathrm{~mm}$ Hg group). Outcome measures included intra-operative cardiopulmonary parameters, operating time, postoperative pain and morbidity, and, liver function tests. Minimally invasive intra-operative cardiovascular monitoring was used. Analysis was by Student's t-test, ANOVA F-test and the Turkey procedure.
\end{abstract}

Results: Demographic parameters, operation time, conversion rate and postoperative hospital stay were similar in both the groups. Port placement at $8 \mathrm{mmHg}$ pressure was difficult; in 6 , pressure was increased to $12 \mathrm{mmHg}$. No significant complications or mortality were observed. Low pressure PP was significantly better in terms of pain scores (at 3, 6, 12, 24 hours; $p=0.01$ ) number of additional doses of analgesic used $(0.3 \pm 0.6$ vs $1.0 \pm 0.74 \mathrm{mg}$ tramadol; $\mathrm{p}=0.00)$, and, total extra dose of analgesic used $(15 \pm 29.80$ vs $50 \pm 37.14 \mathrm{mg}$ tramadol; $\mathrm{p}=0.00$ ). Some differences in favour of the low pressure group were observed for arterial to end-tidal CO2 gradient, serum bilirubin and serum alanine tranferase; however, no significant differences were observed in cardiopulmonary parameters or liver function tests.

Conclusions: Laparoscopic cholecystectomy is feasible and safe at $8 \mathrm{mmHg}$ pressure with slight modification of technique, and is associated with less pain compared to surgery at $12 \mathrm{mmHg}$. Studies with compromised cardiopulmonary or hepatic reserve are required to better quantify the benefits.

Key words: Low Pressure Pneumoperitoneum; Standard Pressure Pneumoperitoneum; Laparoscopic Cholecystectomy; Pain, Operative Difficulty; Pulse Waveform Analysis

\section{Introduction}

Laparoscopic cholecystectomy (LC) has been established as the gold standard for the treatment of uncomplicated symptomatic gallstone. Creation of pneumoperitoneum (PP) by carbon dioxide $\left(\mathrm{CO}_{2}\right)$ insufflation is the most widely accepted technique for adequate working space and patient safety $[1,2$, 3]. The standard pressure for PP lies between 12-15 mm Hg; however, decreased pulmonary compliance, altered blood gas parameters, decrease in cardiac output, impaired renal perfusion and raised liver enzymes have been observed at these pressures. $[4,5,6]$. These effects may be explained by decrease in renal, hepato-portal and splanchnic blood flows, along with impairment of venous return during PP.

Several studies have compared the effects of reduced pressure (7-9 $\mathrm{mm} \mathrm{Hg}$ ) with standard pressure (12-15 mm $\mathrm{Hg}$ ) during LC [7-11]. These studies illustrate the feasibility of low pressure PP, along with some advantages in terms of postoperative pain. However, it is still unclear whether changes in metabolic and physiologic parameters viz. liver function tests and cardiopulmonary parameters, have any clinical significance [11]. Joshipura and colleagues have performed the only randomized trial on the subject from our country; incidentally, they are also amongst the few to have commented on the operative challenges faced by reducing the pressure [12].

The present study was designed to compare low pressure and standard pressure pneumoperitoneum used during LC in terms of intra-operative parameters (cardiopulmonary, metabolic), operative difficulty, postoperative pain, consumption of analgesics and liver profile derangement.

\section{Patients and Methods}

This study was a prospective, randomized, tripleblinded trial conducted in a tertiary care teaching hospital in 
Delhi, India, between 2011 and 2013. The study was undertaken after approval by the institutional ethics committee, and after obtaining informed written consent from all the subjects. For the purpose of the study, low-pressure pneumoperitoneum laparoscopic cholecystectomy (LPLC) was denoted when insufflation pressure was kept at $8 \mathrm{mmHg}$; and high-pressure pneumoperitoneum laparoscopic cholecystectomy (HPLC) when insufflation pressure was kept at $12 \mathrm{mmHg}$ after the introduction of all four ports.

Patients with a diagnosis of symptomatic uncomplicated gallstone disease, scheduled for elective laparoscopic cholecystectomy were enrolled in the study. Patients with deranged liver function tests (including serum alkaline phosphatase), history of chronic liver disease or liver malignancy, history of chronic alcohol intake, history of jaundice, cardiopulmonary disease, morbid obesity, choledocholithiasis, biliary obstruction, cholangitis, carcinoma gallbladder, a recent ( $<3$ weeks)or ongoing episode of acute gallstone pancreatitis or acute cholecystitis, ongoing pregnancy, bleeding diathesis, or upper abdominal surgical scars were excluded from the study.

After admission, the following information was recorded on the case record form - age, sex, weight, height, body mass index (BMI), pre-operative ultrasound findings (wall thickness, pericholecystic fluid, common duct anatomy and diameter, and number of calculi), and, liver function tests (serum total bilirubin, serum alanine aminotransferase, serum alkaline phosphatase).

The subjects were randomized using computergenerated random numbers into one of two groups depending on the insufflation pressure used - group 1 (LPLC or $8 \mathrm{~mm} \mathrm{Hg}$ group), and, group 2 (HPLC or $12 \mathrm{~mm} \mathrm{Hg}$ group). Allocation concealment was achieved by the sealed envelope technique. The envelopes were opened in the operating room by technical staff responsible for setting the insufflation pressure.

After overnight fasting, patients received premedication with oral diazepam $0.2 \mathrm{mg} / \mathrm{kg} 2$ hours before surgery, and, a single dose of prophylactic antibiotic (intravenous cefazolin) at induction of anesthesia. Intra-operative monitoring included continuous lead II electrocardiography, pulse oximetry, capnography, and spirometry (S5 monitor, DatexOhmeda®, USA). Radial artery cannulation was performed after confirming adequate collateral flow in the ulnar artery by the modified Allen's test. The arterial cannula was connected to a FloTrac ${ }^{\mathrm{TM}}$ sensor and Vigileo $^{\mathrm{TM}}$ monitor (Edwards Lifesciences®, USA). This enabled minimally-invasive measurement of mean arterial pressure, heart rate, and, cardiac index, using a validated pulse waveform analysis $[13,14]$. The principle involved is that aortic pulse pressure is proportional to stroke volume and inversely proportional to aortic compliance.

Following establishment of monitoring, an intravenous crystalloid infusion (Ringer's lactate) was initiated at $10 \mathrm{~mL} /$ $\mathrm{kg} /$ hour. Anesthesia was induced using intravenous fentanyl 1-2 $\mu \mathrm{g} / \mathrm{kg}$ with intravenous propofol $1-2.5 \mathrm{mg} / \mathrm{kg}$, and tracheal intubation was facilitated by intravenous vecuronium $0.1 \mathrm{mg} / \mathrm{kg}$ as muscle relaxant. Anesthesia was maintained with a mixture of $\mathrm{O}_{2}$ and $\mathrm{N}_{2} \mathrm{O}$ along with isoflurane $(1 \pm 0.1 \mathrm{MAC})$. Intra-operative drug dosages, fluids, and $\mathrm{FiO}_{2}$ were titrated to maintain heart rate and blood pressure at $\pm 20 \%$ of baseline values, and $\mathrm{SpO}_{2}$ greater than $97 \%$. Intra-operative ventilation was standardized in both groups using volume-controlled mode initiated at a tidal volume of $8 \mathrm{~mL} / \mathrm{kg}$, I:E ratio of 1:2 and a respiratory rate of 10 breaths per minute. Keeping tidal volume constant, eucapnia (end-tidal $\mathrm{CO}_{2}=35-40 \mathrm{mmHg}$ ) was maintained by varying the respiratory rate.

Hemodynamic variables viz. mean arterial pressure; heart rate and cardiac index were recorded prior to induction of anesthesia (basal), post-induction, and then every 10 minutes following creation of pneumoperitoneum until completion of the procedure. Ventilatory parameters viz. end-tidal $\mathrm{CO}_{2}$, mean airway pressure, peak airway pressure, SpO2, tidal volume, respiratory rate and I:E ratio were recorded postinduction following intubation, and at 10 minute-intervals until completion of the procedure. Arterial blood gases analysis was performed post-induction (baseline), and then at 20 minutes post-pneumoperitoneum. Muscle relaxation was reversed with intravenous neostigmine $0.05 \mathrm{mg} / \mathrm{kg}$ and atropine $0.02 \mathrm{mg} /$ $\mathrm{kg}$. Ondansetron $8 \mathrm{mg}$ and ranitidine was administered for postoperative nausea and vomiting.

An operating room technician set the insufflator to the pressure indicated in the sealed envelope, and covered the display of the insufflator with adhesive strips paper to effectively achieve triple blinding (surgeon, patient, and evaluator). Cholecystectomy was performed by any one of four surgeons, with a minimum experience of 200 cases each. The standard four-port technique was used; pneumoperitoneum was created by the open method and the pressure was set to the randomized value from the outset. Patients were placed in a reverse Trendelenberg position $\left(30^{\circ}\right)$ with $15^{\circ}$ elevation of the right shoulder after introduction of the four ports. If the surgeon was unable to proceed further due to poor visualization, he/she requested for an increase in pressure. The pressure was increased by the same technician to $12 \mathrm{~mm} \mathrm{Hg}$ (if $8 \mathrm{~mm} \mathrm{Hg}$ earlier), or was kept at $12 \mathrm{~mm} \mathrm{Hg}$ ('sham' increase). This ensured continuation of blinding throughout the procedure. Conversion to open surgery was done only after the surgeon was convinced that further dissection was not possible at the second pressure, or there was another anatomical/ technical difficulty in the case (during grasping of fundus, dissection of Calot's triangle, clipping of duct or artery, separation from liver bed, or extraction of the organ). All such events and the time at which the difficulty encountered were recorded. Injuries to CBD, gall bladder perforation, eletrocautery burns to parietal wall/ viscera were recorded. Intra-operative outcome parameters recorded were operating time (laparoscopic time only), conversion to higher pressures, conversion to open surgery, reasons for conversion, intra-operative injuries or mortality, and use of additional ports.

Postoperative analgesia in the form of intramuscular diclofenac $1.25 \mathrm{mg} / \mathrm{kg} 8$ hourly for 24 hours was administered to all patients. Patients requesting for additional pain relief 
were prescribed intravenous tramadol (50 $\mathrm{mg}$ ). The numbers of additional doses of analgesic, as well as the total additional dose used were recorded. Postoperative pain was also assessed by a visual analogue pain scale (VAS) at 3 hours, 12 hours, 24 hours and 48 hours after surgery. Pain scores were graded from 0 (no pain) to 10 (unbearable pain). The patients were discharged 24 hours after surgery if the course was unremarkable. Liver function tests were repeated on postoperative day 1 and day 7 . Postoperative parameters recorded were surgical site infection, bile leak, port site hernia, prolonged ileus $>24 \mathrm{hrs}$, peritonitis, re-operation, postoperative jaundice, or, death.

\section{Statistical analysis}

The sample size was calculated at an $80 \%$ power and $\alpha$ error of $5 \%$, to detect a $35 \%$ difference in pain score, taking account of previously reported VAS scores during laparoscopic cholecystectomy at different pressures.[15,16] Analysis was based on the intention-to-treat principle. The Student's t-test was used to compare continuous variables between the two groups. The ANOVA F-test and the Tukey procedure were used for comparison of parameters with repeated measures within the group, and between groups. All data were analysed using SPSSTM software version 17.0 (SPSS Inc, Chicago, Il, USA). All reported $\mathrm{p}$ values were 2 -tailed and $\mathrm{p}<0.05$ was considered statistically significant.

\section{Results}

Sixty patients of symptomatic gallstone disease planned for laparoscopic cholecystectomy were included in the study. After randomization, there were 30 patients in both groups, i.e. group 1 (LPLC or $8 \mathrm{~mm} \mathrm{Hg}$ group), and, group 2 (SPLC or $12 \mathrm{~mm}$ $\mathrm{Hg}$ group). Both groups were similar with respect to age, sex and BMI (Table 1). There were no associated co-morbidities in any of the patients.

Table 1: Demographic features, intra-operative difficulty and postoperative course in both groups

\begin{tabular}{|c|c|c|c|}
\hline & LPLC group & SPLC group & $p$ value (significant if $<0.05$ ) $*$ \\
\hline Age in years (mean) & $33.83 \pm 14.15$ & $38.93 \pm 13.09$ & 0.807 \\
\hline Sex ratio (male: female) & $3: 27$ & $3: 27$ & 1 \\
\hline BMI $(\mathrm{kg} / \mathrm{m} 2)$ & $22.89 \pm 4.18$ & $22.53 \pm 3.76$ & 0.983 \\
\hline $\begin{array}{l}\text { Length of postoperative hospital stay } \\
\text { (days) }\end{array}$ & $1.43 \pm 0.63$ & $1.40 \pm 0.50$ & 0.82 \\
\hline Operating time (minutes) & $60 \pm 17.76$ & $58.87 \pm 21.08$ & 0.823 \\
\hline Conversion rate & $10 \%(3 / 30)^{\wedge}$ & $6.66 \%(2 / 30)$ & 0.177 \\
\hline $\begin{array}{l}\text { Number of additional doses of } \\
\text { analgesic }\end{array}$ & $0.30 \pm 0.60$ & $1.00 \pm 0.74$ & 0.000 \\
\hline $\begin{array}{l}\text { Total extra dose of analgesic ( } \mathrm{mg} \text { of } \\
\text { tramadol) }\end{array}$ & $15 \pm 29.80$ & $50 \pm 37.14$ & 0.000 \\
\hline
\end{tabular}

*chi-square or t-test used, as applicable. BMI - body mass index, LPLC - low-pressure pneumoperitoneum laparoscopic cholecystectomy, SPLC standard-pressure pneumoperitoneum laparoscopic cholecystectomy. All values (except sex ratio and conversion rate) in mean \pm SD. ^ cases where conversion due to factors other than low pressure.

In the LPLC group, difficulty was encountered by all the operating consultants in placing the $2^{\text {nd }}-4^{\text {th }}$ ports $\left(1^{\text {st }}\right.$ port by open technique) using the standard $100 \mathrm{~mm}$ trocars. This was partly circumvented by making slightly oblique tracts. Other areas of difficulty were - while grasping the gall bladder fundus in 14 patients, during dissection of Calot's triangle in 22 patients, while clipping the cystic duct in 3 patients, and, while dissecting the gallbladder off the liver bed in 9 cases. Despite this, 21 of 30 cases were completed at $8 \mathrm{~mm} \mathrm{Hg}$ pressure. Minor adjustments were made in a few instances (like using $30^{\circ}$ telescope); however, additional ports were not required in any case. In 6 cases, the pressure was raised to $12 \mathrm{~mm} \mathrm{Hg}$, and 3 of these were converted to open cholecystectomy despite raising the pressure. Three patients needed conversion to open cholecystectomy for other reasons. Hence, the overall conversion rate to open procedure was $6 / 30$ (20\%); half (3/30-10\%) were attributable to low pressure and poor visualization.
In the SPLC group too, there was difficulty encountered at various stages (creation of pneumoperitoneum: 2 cases, grasping gallbladder fundus: 3 cases, dissection of Calot's: 9 patients, clipping of cystic duct: 1 case, and, dissection of gall bladder from bed: 9 cases). Here, 28 cases were completed at $12 \mathrm{~mm} \mathrm{Hg}$. Two cases (7\%) were converted to open cholecystectomy due to difficult anatomy and adhesions.

No significant intra- or postoperative complications were observed in either group. There were no significant differences between the groups in operating time, conversion rate (due to factors other than pressure), and, the length of postoperative hospital stay (Table 1).

\section{Cardiopulmonary Parameters}

For statistical analysis of the repeated intraoperative cardiopulmonary parameters, readings have been truncated at 40 minutes post-pneumoperitoneum. Beyond this time, there 
was a significant attrition of data due to completion of surgery in several patients.

Heart rate decreased significantly after induction and creation of pneumoperitoneum in both groups; a slight increase was seen with the duration of pneumoperitoneum, however, there was no significant difference between the two groups ( $p=0.714)$ (Table 2). In both the groups, mean arterial pressure (MAP) was reduced after induction but increased above the baseline after creation of pneumoperitoneum; however, there was no significant difference between the two groups $(\mathrm{p}=0.632)$. In both groups, cardiac index decreased after induction, but was seen to increase gradually with the duration of pneumoperitoneum. The increase was more in the standard pressure group, however, the difference was not statistically significant $(p=0.730)$. The absolute values of all parameters were within the clinically normal range.

\begin{tabular}{|c|c|c|c|c|c|c|}
\hline & \multicolumn{2}{|l|}{ LPLC group } & \multirow[b]{2}{*}{$\begin{array}{l}\text { Cardiac index (L/ } \\
\mathrm{min} / \mathrm{m} 2)\end{array}$} & \multicolumn{2}{|l|}{ SPLC group } & \multirow[b]{2}{*}{$\begin{array}{l}\text { Cardiac index }(\mathrm{L} / \\
\min / \mathrm{m} 2)\end{array}$} \\
\hline & $\begin{array}{l}\text { Heart rate } \\
(\mathrm{bpm})\end{array}$ & $\begin{array}{l}\text { Mean Arterial } \\
\text { Pressure (mm Hg) }\end{array}$ & & $\begin{array}{l}\text { Heart rate } \\
(\mathrm{bpm})\end{array}$ & $\begin{array}{l}\text { Mean Arterial } \\
\text { Pressure (mm Hg) }\end{array}$ & \\
\hline Basal & $84 \pm 9$ & $90 \pm 13$ & $4.4 \pm 1.0$ & $85 \pm 12$ & $91 \pm 14$ & $4.2 \pm 1.4$ \\
\hline Post-induction & $80 \pm 12$ & $86 \pm 14$ & $4.0 \pm 1.3$ & $84 \pm 15$ & $89 \pm 14$ & $3.9 \pm 1.1$ \\
\hline $10 \mathrm{~min} \#$ & $77 \pm 10$ & $92 \pm 13$ & $3.9 \pm 1.0$ & $77 \pm 10$ & $95 \pm 8$ & $4.2 \pm 1.2$ \\
\hline $20 \mathrm{~min} \#$ & $78 \pm 10$ & $92 \pm 12$ & $3.7 \pm 0.9$ & $77 \pm 10$ & $92 \pm 10$ & $4.1 \pm 1.3$ \\
\hline $30 \mathrm{~min} \#$ & $78 \pm 8$ & $93 \pm 13$ & $4.0 \pm 1.0$ & $78 \pm 10$ & $93 \pm 10$ & $4.3 \pm 1.3$ \\
\hline $40 \mathrm{~min} \#$ & $79 \pm 9$ & $93 \pm 12$ & $4.1 \pm 0.9$ & $79 \pm 11$ & $91 \pm 8$ & $4.3 \pm 1.2$ \\
\hline
\end{tabular}

Values are mean \pm standard deviation; LPLC group: low pressure pneumoperitoneum; SPLC: standard pressure pneumoperitoneum; \# the designated time interval (minutes) following creation of pneumoperitoneum
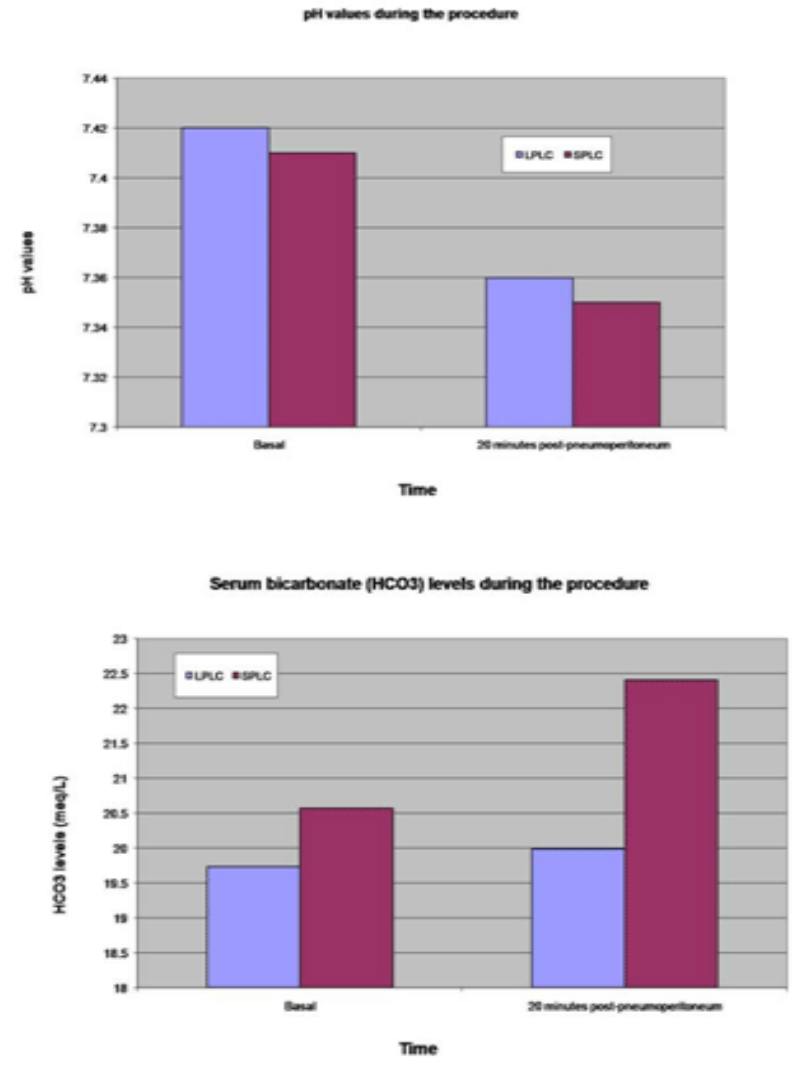
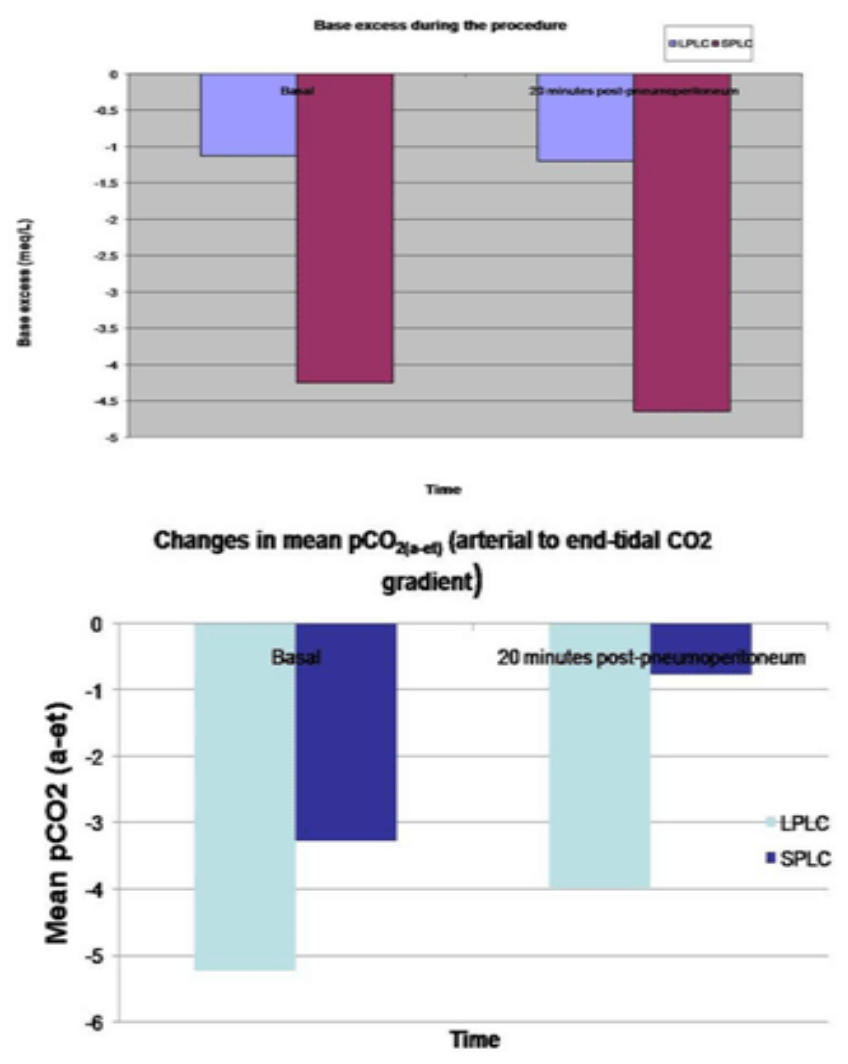

Figure 1: Mean and peak airway pressures, and, $\mathrm{pO}_{2}$ and $\mathrm{pCO}_{2}$ levels during the procedure in both groups

Citation: Agarwal Nitin, et al. (2017) Feasibility and Safety of Low Pressure Pneumoperitoneum for Laparoscopic Cholecystectomy: A Prospective, Randomized, Triple-Blinded Trial. Gastroenterol Pancreatol Liver Disord 4(4):1-8 DOI: http://dx.doi.org/10.15226/2374- 
Using volume-controlled ventilation, the anesthesia team maintained a constant tidal volume (TV) throughout the procedure. The respiratory rate (RR) was titrated upwards from 10 breaths per minute to maintain eucapnia (end-tidal CO2 35$40 \mathrm{~mm} \mathrm{Hg}$ ). Hence, the TV, RR, and end-tidal CO2 were similar in both groups. The mean and peak airway pressures were seen to rise in both groups after PP; a marginally higher peak airway pressure was seen in the SPLC group after 30 minutes, however, the difference was not statistically significant $(p=0.729)$ (Figure 1).
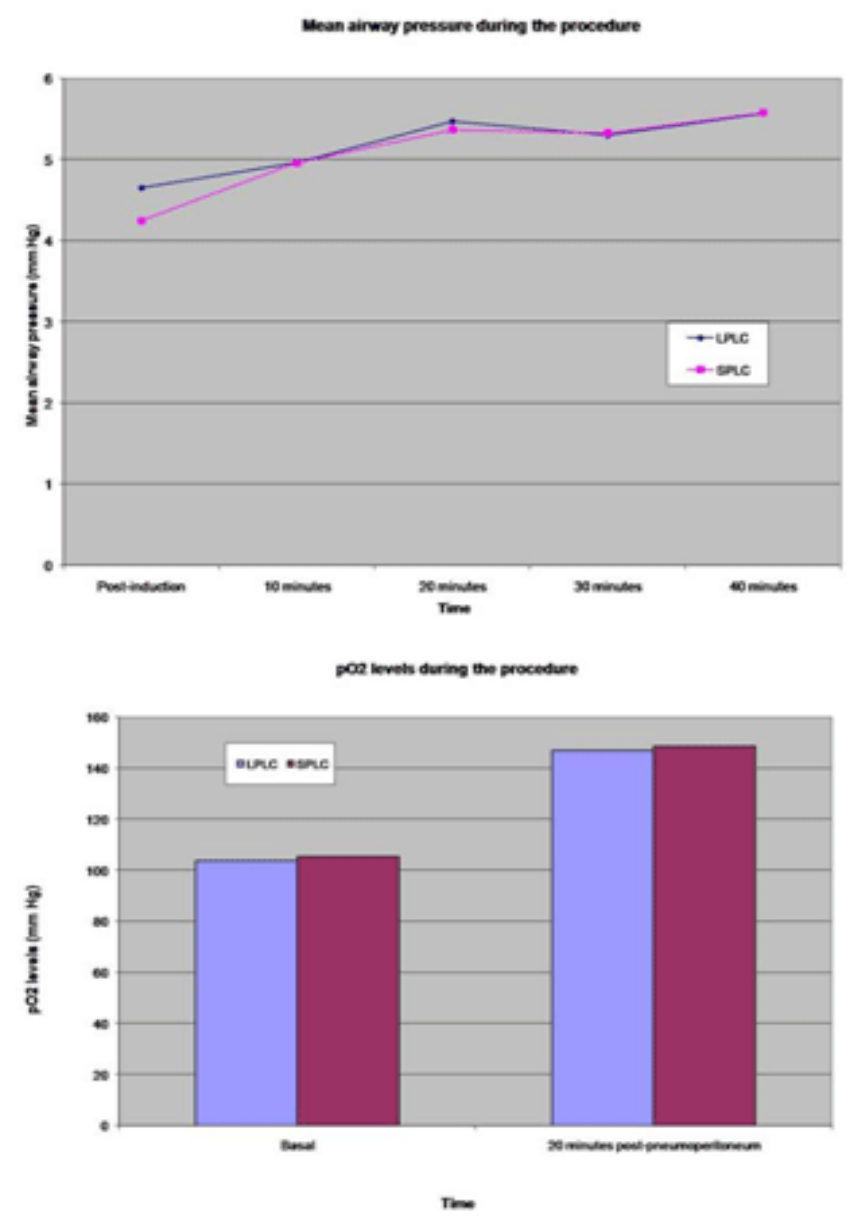

Arterial blood gas analysis revealed a rise in $\mathrm{pO}_{2}$ and $\mathrm{pCO}_{2}$ (Figure 1) levels after 20 minutes of PP, which were significant within the groups, but not between the two groups. These changes were paralleled by a significant fall in $\mathrm{pH}$ and base excess values (Figure 2) in both groups, with no significant differences between the groups ( $p>0.05)$. None of the changed values were of clinical relevance. While a minimal change in arterial bicarbonate (Figure 2) values was seen in the LPLC group, a slight increase $(\sim 1.8$ meqL-1) was noted in the SPLC group, possibly due to the greater $\mathrm{pCO}_{2}$ levels in this group. The differences between the groups were statistically significant $(\mathrm{p}=0.030)$.
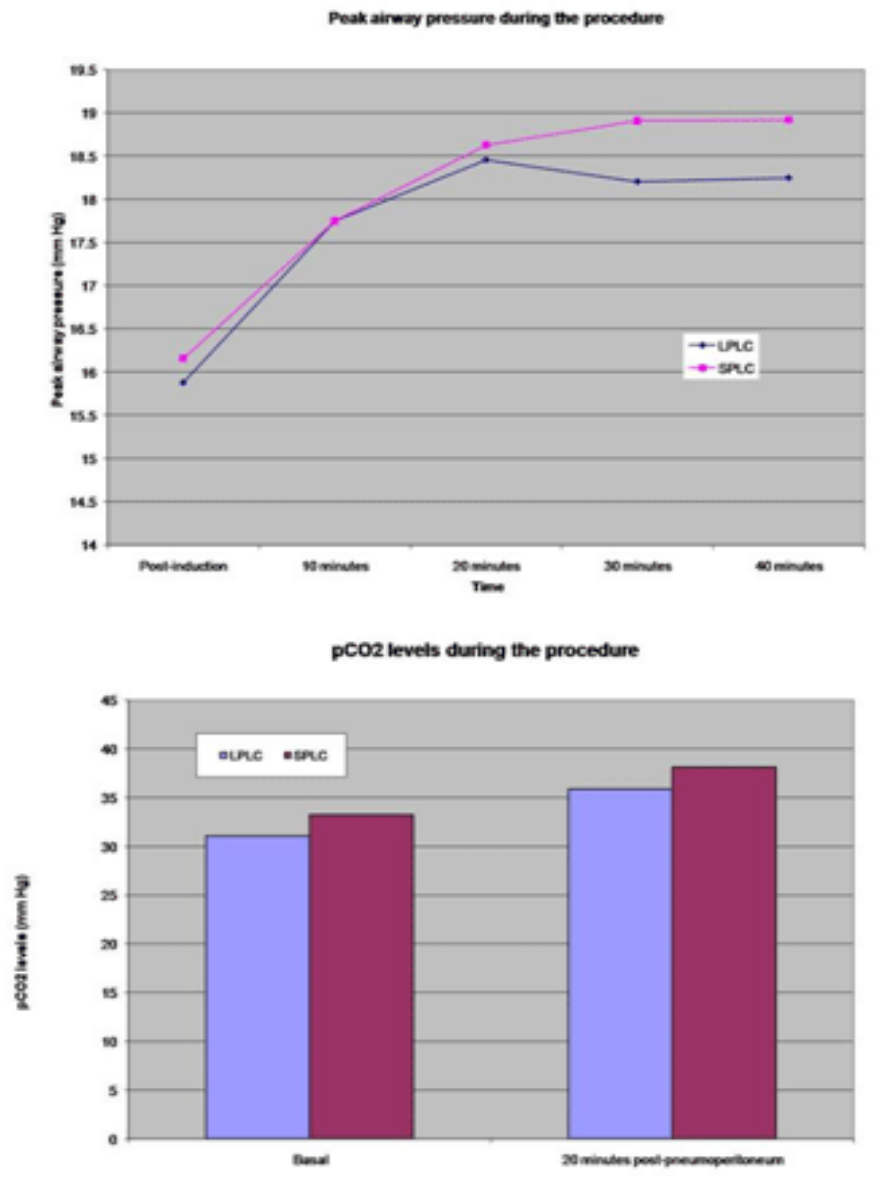

Figure 2: Arterial $\mathrm{pH}$, base excess, arterial to end-tidal $\mathrm{CO}_{2}$ gradient, and serum bicarbonate levels during the procedure in both groups

The mean $\mathrm{pCO}_{2(\mathrm{a}-\mathrm{et})}$ (arterial to end-tidal $\mathrm{CO} 2$ gradient, Figure 2) was seen to change by $1.36 \mathrm{~mm} \mathrm{Hg}$ in the LPLC group, and by $2.50 \mathrm{~mm} \mathrm{Hg}$ in the SPLC group after 20 minutes of PP, however, the difference was not statistically significant $(\mathrm{p}>0.05)$.

\section{Pain}

In both groups, the VAS score was maximum at 6 hours postoperatively; and gradually decreased with time (Figure 3). Pain scores were significantly higher $(\mathrm{p}=0.01)$ in the SPLC group on all 4 occasions. In the LPLC group, 7 patients (23\%) required additional doses of analgesics; the total additional dose was $450 \mathrm{mg}$ (five needed $50 \mathrm{mg}$ oral tramadol while 2 needed 100 $\mathrm{mg}$ ). In the SPLC group, 22 patients $(73 \%)$ required additional doses; the total additional dose was $1550 \mathrm{mg}$ (13 needed 50 mg while 9 needed $100 \mathrm{mg}$ ). There were significant differences between the two groups with respect to number of additional doses of analgesic (tramadol) used $(\mathrm{p}<0.001)$, as well as the total additional dose of analgesic used $(\mathrm{p}<0.001)$. (See Table 1$)$ 


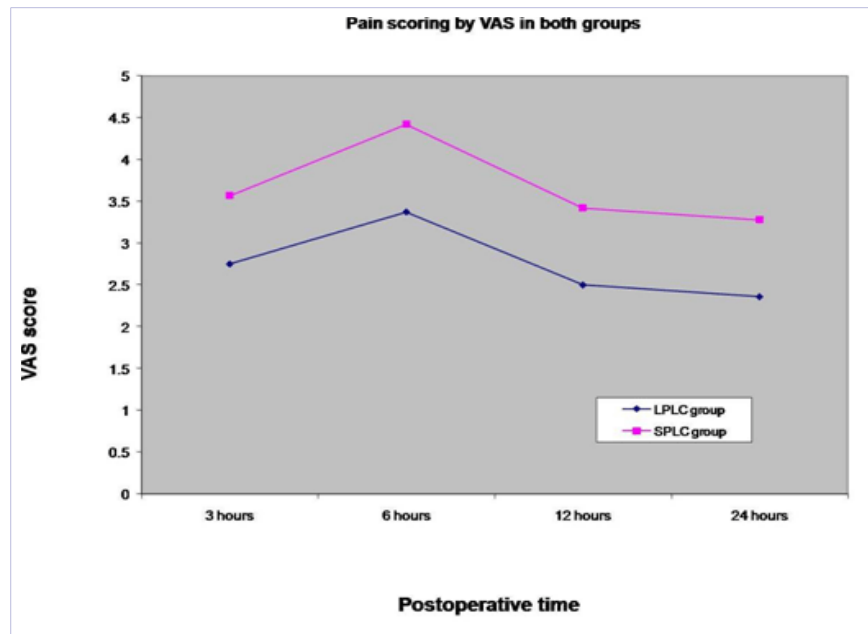

Figure 3: Postoperative pain scores by visual analogue scale (VAS) in both the groups

\section{Liver function tests}

Serum total bilirubin and serum alanine transferase rose significantly in the SPLC group on postoperative day 1, and then returned to near-baseline values by postoperative day 7. (Table 3) No value was seen to lie outside clinically relevant range. There were no significant changes between the two groups with regard to all 3 liver function tests ( $p>0.05)$.

\section{Discussion}

In the LPLC group, we did encounter difficulty in placing the 2nd-4th ports. As mentioned, this problem was partly circumvented by initially piercing the anterior abdominal fascia with a blade, and by sometimes using slightly oblique tracts. Anticipating this, others in similar situations have used a higher pressure initially for port placement $[7,9,12,16]$. We feel that the higher initial pressure might confound the cardiopulmonary variables in the LPLC group. Overall, port placement did not seem

Table 3: Changes in values of liver function tests in both groups

\begin{tabular}{|c|c|c|c|c|c|c|}
\hline & \multicolumn{2}{|l|}{ LPLC group } & \multirow[b]{2}{*}{$\begin{array}{l}\text { Serum alkaline } \\
\text { phosphatase } \\
\text { (U/L) }\end{array}$} & \multicolumn{2}{|l|}{ SPLC group } & \multirow[b]{2}{*}{$\begin{array}{l}\text { Serum alkaline } \\
\text { phosphatase } \\
\text { (U/L) }\end{array}$} \\
\hline & $\begin{array}{l}\text { Serum total } \\
\text { bilirubin (mg/ } \\
\text { dL) }\end{array}$ & $\begin{array}{l}\text { Serum alanine } \\
\text { aminotranferase } \\
\text { (IU/L) }\end{array}$ & & $\begin{array}{l}\text { Serum total } \\
\text { bilirubin } \\
(\mathrm{mg} / \mathrm{dL})\end{array}$ & $\begin{array}{l}\text { Serum alanine } \\
\text { aminotranferase } \\
(\mathrm{IU} / \mathrm{L})\end{array}$ & \\
\hline Pre-operative & $0.697 \pm 0.345$ & $31.43 \pm 19.08$ & $174.74 \pm 56.43$ & $0.635 \pm 0.348$ & $36.04 \pm 29.40$ & $141.38 \pm 114.84$ \\
\hline $\begin{array}{l}\text { Postoperative } \\
\text { day } 1\end{array}$ & $0.765 \pm 0.349$ & $51.65 \pm 29.71$ & $169.39 \pm 46.88$ & $0.939 \pm 0.369$ & $63.41 \pm 41.02$ & $145.88 \pm 74.28$ \\
\hline $\begin{array}{l}\text { Postoperative } \\
\text { day } 7\end{array}$ & $0.660 \pm 0.189$ & $37.78 \pm 18.94$ & $167.17 \pm 51.88$ & $0.670 \pm 0.190$ & $49.29 \pm 29.69$ & $127.25 \pm 49.71$ \\
\hline
\end{tabular}

an insurmountable hurdle, as evidenced from the comparable operating times and conversion rates. Objective comparison of surgical difficulty at different pressures of PP has been performed by only one group $[11,12]$. Joshipura et al compared three parameters related to operative comfort, i.e. vision, space for dissection, and vision while using suction. They observed differences in favor of the higher pressure group in all three parameters, but these were not statistically significant [12]. In other studies, more than $85 \%$ of LCs were completed in patients randomized to the low pressure group. No differences have been reported in the requirement for additional ports, conversion rate, operating time, or complication rates $[10,11,17]$.

Cardiovascular changes in laparoscopic cholecystectomy occur due to anesthesia, CO2 PP, and patient positioning. In our patients, the degree of tilt, both in the reversed Trendelenberg position and the right-up position, was kept constant for all patients. At the start of PP, increased intraabdominal pressure (IAP) compresses blood out of the splanchnic vasculature, increases the venous return and preload, and hence there is increase in the mean arterial pressure (MAP), systemic vascular resistance (SVR) and pulmonary vascular resistance (PVR), accompanied with a decrease in cardiac output (CO) $[6,18]$. SVR elevation may also be due to increased plasma renin activity, increased antidiuretic hormone (ADH) production, and influence of the sympathetic system. Increased MAP is associated with elevated right atrial pressure (RAP) and pulmonary capillary wedge pressure (PCWP). Hypotension may occur in relatively hypovolemic patients, when increased IAP along with intermittent positive pressure ventilation (IPPV) compresses the inferior vena cava (IVC) and raises the intrathoracic pressure. The reverse Tredelenburg position also reduces venous return, leading to reduced CO and MAP. At lower IAP, cardiovascular changes are less pronounced. All the parameters have been shown to be reversible after peritoneal exsufflation without any residual effects [19].

Only a few studies have dealt with comparison of cardiopulmonary parameters at different pressures of PP $[7,8$, $12,20,21]$. Wallace et al in a prospective, randomized doubleblinded study of 40 patients showed that there were no significant differences in intraoperative heart rate or cardiac index, although the latter fell significantly soon after insufflation in both groups. The fall in cardiac index lasted longer (7 vs 2 minutes) and 
coincided with a slower rise in mean arterial pressure in the group with higher insufflation pressure. The authors felt that the hemodynamic effects of carbon dioxide are overshadowed by the mechanical effects of increased intra-abdominal pressure during laparoscopy [8]. Dexter et al found a moderate increase in heart rate after peritoneal insufflation which reached statistical significance for the high pressure group. The MAP also rose significantly in both groups. Stroke volume (SV) and cardiac output (CO) were reduced after PP in both groups, however, both $\mathrm{SV}$ and CO were significantly higher $(\mathrm{p}<0.04)$ subsequently in the low pressure group [7]. In our patients, the values of MAP and CI do suggest a similar trend of reduction after PP, however, no significant effects of differential pressure is observed.

It can be inferred that these pathophysiological responses can be deleterious, especially in individuals with compromised hemodynamic status (ASA III and IV patients). Preventive measures like preoperative volume loading (10$12 \mathrm{~mL} / \mathrm{kg}$ ) may prevent a decrease in CO that is induced by high IAP with reverse Tredelenburg position. In ASA III and IV patients, invasive hemodynamic monitoring or transesophageal echocardiography (TEE) may be necessary for optimal outcomes. The rate and pressure of $\mathrm{CO}_{2}$ insufflation may be reduced to prevent vasovagal and other dangerous cardiovascular responses [6].

Due to high solubility in blood, CO2 is rapidly absorbed during PP, inducing hypercapnia and acidosis. The end-tidal $\mathrm{CO}_{2}$ concentrations increase initially, however, $\mathrm{CO}_{2}$ tends toaccumulate in the body during prolonged surgery and due to high IAP. This can be reliably excreted only by compensatory hyperventilation, as the renal excretion of excessive $\mathrm{H}+$ is a much slower response (3-5 days).[6,22] Despite increasing the tidal volume of ventilation, respiratory acidosis and increased $\mathrm{CO}_{2}$ excretion persists up to $1 \mathrm{hr}$ postoperatively. In patients with compromised cardiopulmonary function, $\mathrm{CO}_{2}$ retention may reach dangerous levels.[22]

Increased IAP leads to increased intrathoracic pressure, restricting lung expansion and decreasing functional residual lung capacity by up to $50 \%$. The peak and plateau airway pressures are increased, leading to increased ventilationperfusion mismatch and intrapulmonary shunting. This may worsen the risk for developing hypoxemia in patients of chronic obstructive pulmonary disease (COPD).[22,23] The anesthesiologist usually attempts to avoid hypercapnia and acidosis by increasing the tidal volume or by using positive end-expiratory pressure (PEEP), however, overuse of these maneuvers can cause ventilator-induced lung injury or further reduction of cardiac output, respectively. The routine use of other gases like argon, helium, etc., is still under study. Sefr et al found no significant differences in $\mathrm{pH}, \mathrm{pCO}_{2}, \mathrm{pO}_{2}$, base excess, and $\mathrm{HCO}_{3}$ - levels between the two groups randomized for different pressures of PP.[20] They concluded that PP negatively influences acid-base changes, however, whether these changes are more due to high IAP or transperitoneal $\mathrm{CO}_{2}$ absorption, is not clear. In a similar trial, Joshipura and colleagues found no significant changes in $\mathrm{pCO}_{2}$, total $\mathrm{CO}_{2}, \mathrm{pH}$, base excess, and $\mathrm{HCO}_{3}$ - levels. [12] They noticed differences in pO2 and end-tidal CO2 levels; however, we regard these parameters as modifiable and have not included them for objective comparisons. In a systematic review of randomized clinical trials comparing different pressures of PP in patients undergoing LC, Gurusamy and colleagues [11] found no differences in heart rate, mean arterial pressure, cardiac index, and arterial pH between the two groups. They concluded that there is insufficient information about the cardiopulmonary benefits of low pressure PP, and further trials are required, particularly inclusive of patients with higher ASA grades in terms of cardiopulmonary morbidity.

We have compared the mean arterial to end-tidal $\mathrm{CO}_{2}$ gradient $\left(\mathrm{pCO}_{2}(\mathrm{a}-\mathrm{et})\right)$, which is a better indicator of ventilationperfusion mismatch in the lungs, and is expected to change due to basal lung compression in PP.[24] No previous study has dealt with this parameter.

Pain after laparoscopic cholecystectomy may be due to several mechanisms; [15] viz. the incision sites, peritoneal stretching, or, from the surgical trauma. Diaphragmatic irritation due to surgical drains or bile is also believed to play role, especially with regard to shoulder-tip pain.[9] Higher pressures of PP are believed to predispose to worse pain scores after LC. After adequate blinding of patients to eliminate bias, two studies report significant decrease in overall pain with low pressure PP. [8,9] Gurusamy et al, in their systematic review, believe the main advantage of low pressure PP is, in fact, decreased pain.[11] This is probably the only positive result in our study too.

We noticed transient elevation of serum bilirubin and serum alanine aminotransferase in both groups of patients, however, these elevations were not clinically or statistically significant. Retardation of hepatic blood flow by PP is postulated to cause elevation in liver enzymes, though not to clinically significant levels. [25] These changes have been shown to be independent of direct trauma to the liver. [26,27] Higher pressures during PP have been shown to produce more marked changes in liver function tests. [26,28] However, none of these studies have reported clinically significant changes. This leads to the conclusion that cautious use of higher PP pressure is prudent, especially when liver function is compromised.

\section{References}

1. Gurusamy KS, Koti R, Samraj K, Davidson BR. Abdominal lift for laparoscopic cholecystectomy. Cochrane Database Syst Rev. 2012;5:CD006574. doi:10.1002/14651858.CD006574.pub2

2. Menes T, Spivak H. Laparoscopy: searching for the proper insufflation gas. Surg Endosc. 2000;14(11):1050-1056.

3. Neuhaus SJ, Gupta A, Watson DI. Helium and other alternative insufflations gases for laparoscopy. Surg Endosc. 2001;15(6): 553560 .

4. Baraka A, Jabbour S, Hammoud R, Aouad M, Najjar F, Khoury G, et al. End-tidal carbon dioxide tension during laparoscopic cholecystectomy. Correlation with the baseline value prior to carbon dioxide insufflation. Anaesthesia 1994;49(4):304-306. 
5. Joris JL, Noirot DP, Legrand MJ, Jacquet NJ, Lamy ML. Hemodynamic changes during laparoscopic cholecystectomy. Anesth Analg. 1993;76(5):1067-1071.

6. Henny CP, Hofland J. Laparoscopic surgery: pitfalls due to anesthesia positioning, and pneumoperitoneum. SurgEndosc. 2005;19(9):11631171.

7. Dexter SP, Vucevic M, Gibson J, McMahon MJ. Hemodynamic consequences of high- and low-pressure capnoperitoneum during laparoscopic cholecystectomy. Surg Endosc. 1999;13(4):376-381

8. Wallace DH, Serpell MG, Baxter JN, O’Dwyer PJ. Randomized trial of different insufflation pressures for laparoscopic cholecystectomy. Br J Surg. 1997;84(4):455-458.

9. Barczynski M, Herman RM. A prospective randomized trial on comparison of low-pressure (LP) and standard-pressure (SP) pneumoperitoneum for laparoscopic cholecystectomy. SurgEndosc. 2003;17(4):533-538.

10. Koc M,Ertan T, Tez M, Kocpinar MA, Kilic M, Gocmen E, etal. Randomized, prospective comparison of postoperative pain in low- versus highpressure pneumoperitoneum. ANZ J Surg. 2005;75(8):693-696.

11. Gurusamy KS, Samraj K, Davidson BR. Low pressure versus standard pressure pneumoperitoneum in laparoscopic cholecystectomy Cochrane Database Syst Rev. 2009;2:CD006930.

12. Joshipura VP, Haribhakti SP, Patel NR, Naik RP, Soni HN, Patel $\mathrm{B}$, et al. A prospective randomized, controlled study comparing low pressure versus high pressure pneumoperitoneum during laparoscopic cholecystectomy. Surg Laparosc Endosc Percutan Tech. 2009;19(3):234-240.

13. de Waal EE, Kalkman CJ, Rex S, Buhre WF. Validation of a new arterial pulse contour-based cardiac output device. Crit Care Med 2007;35(8):1904-1909.

14. Funk DJ, Moretti EW, Gan TJ. Minimally invasive cardiac output monitoring in the perioperative setting. Anesth Analg 2009;108(3):887-897. doi:10.1213/ane.0b013e31818ffd99

15. Perrakis E, Vezakis A, Velimezis G, Savanis G, Deverakis S, Antoniades J, et al. Randomized comparison between different insufflation pressures for laparoscopic cholecystectomy. SurgLaparoscEndoscPercutan Tech. 2003;13(4):245-249.

16. Chok KS, Yuen WK, Lau H, Fan ST. Prospective randomized trial on lowpressure versus standard-pressure pneumoperitoneum in outpatient laparoscopic cholecystectomy. SurgLaparoscEndoscPercutan Tech 2006;16(6):383-386
17. Davides D, Birbas K, Vezakis A, McMahon MJ. Routine low-pressure pneumoperitoneum during laparoscopic cholecystectomy. SurgEndosc. 1999;13(9):887-889.

18.0'Leary E, Hubbard K, Tormey W, Cunningham AJ. Laparoscopic cholecystectomy: haemodynamic and neuroendocrine responses after pneumoperitoneum and changes in position. $\mathrm{Br} \mathrm{J}$ Anaesth. 1996;76(5):640-644.

19. Gueugniaud PY, Abisseror M, Moussa M, Godard J, Foussat C, Petit P, et al. The hemodynamic effects of pneumoperitoneum during laparoscopic surgery in healthy infants: assessment by continuous esophageal aortic blood flow echo-Doppler. AnesthAnalg. 1998;86(2):290-293.

20.Sefr R, Puszkailer K, Jagos F. Randomized trial of different intraabdominal pressures and acid-base balance alterations during laparoscopic cholecystectomy. SurgEndosc. 2003;17(6):947-950.

21. Ibraheim OA, Samarkandi AH, Alshehry H, Faden A, Farouk EO. Lactate and acid base changes during laparoscopic cholecystectomy. Middle East J Anesthesiol. 2006;18(4):757-768.

22. Hsieh CH. Laparoscopic cholecystectomy for patients with chronic obstructive pulmonary disease. J LaparoendoscAdvSurg Tech A. 2003;13(1):5-9.

23. Rauh R, Hemmerling TM, Rist M, Jacobi KE. Influence of pneumoperitoneum and patient positioning on respiratory system compliance. J ClinAnesth. 2001;13(5):361-365.

24. Choi DK, Lee IG, Hwang JH. Arterial to end-tidal carbon dioxide pressure gradient increases with age in the steep Trendelenburg position with pneumoperitoneum. Korean J Anesthesiol. 2012;63(3):209-215. doi:10.4097/kjae.2012.63.3.209

25.Guven HE, Oral S. Liver enzyme alterations after laparoscopic cholecystectomy. J Gastrointestin Liver Dis. 2007;16(4):391-394.

26. Morino M, Giraudo G, Festa V. Alterations in hepatic function during laparoscopic surgery. An experimental clinical study. SurgEndosc. 1998;12(7):968-972.

27. Tan M, Xu FF, Peng JS, Li DM, Chen LH, Lv BJ, et al. Changes in the level of serum liver enzymes after laparoscopic surgery. World J Gastroenterol. 2003;9(2):364-367. doi: 10.3748/wjg.v9.i2.364

28. Hasukic S. Postoperative changes in liver function tests: randomized comparison of low- and high-pressure laparoscopic cholecystectomy. Surg Endosc. 2005;19(11):1451-1455. 